\author{
(ㄱ. Т.Н. Маркова ${ }^{1,2}$, В.В. Садовская ${ }^{2}$, М.Ю. Беспятова ${ }^{3}$
}

1ГБУЗ Городская клиническая больница №52 Департамента здравоохранения города Москвы, Москва ФГБОУ ВО Московский государственный медико-стоматологический университет им. А.И. Евдокимова Минздрава России, Москва

ГБУЗ Городская поликлиника №115 Департамента здравоохранения города Москвы, Москва

Хроническая болезнь почек (ХБП) - обобщенное понятие, указывающее на поражение почечной ткани вне зависимости от этиологии основного заболевания. ХБП развивается у каждого второго больного сахарным диабетом (СД) и существенно лимитирует продолжительность и качество жизни. Диагностика ХБП проводится по уровню скорости клубочковой фильтрации (СКФ), которая признана как наиболее полно отражающая количество и суммарный объем работы нефронов. Однако снижение СКФ происходит на поздних стадиях нефропатии при необратимых нарушениях функции почек, что в итоге приводит к увеличению затрат на заместительную почечную терапию. В связи с этим ведутся клинические исследования по поиску биомаркеров ХБП, отражающих повреждение почек на более ранних этапах. В статье представлен обзор современных методов диагностики ХБП и доклинических маркеров повреждения почек при СД.

КЛЮЧЕВЫЕ СЛОВА: сахарный диабет; хроническая болезнь почек; доклинические маркеры; скорость клубочковой фильтрации

\title{
MODERN METHODS OF DIAGNOSING CHRONIC KIDNEY DISEASE IN PATIENTS WITH DIABETES MELLITUS
}

(c) Tatiana N. Markova ${ }^{1,2}$, Viktoria V. Sadovskaya², Marina Y. Bespyatova ${ }^{3}$

${ }^{1}$ Municipal clinical hospital №52, Moscow, Russia

${ }^{2}$ Moscow State University of Medicine and Dentistry named after A.I. Evdokimov, Moscow, Russia

${ }^{3}$ City polyclinic № 115, Moscow, Russia

Chronic kidney disease (CKD) is a general concept that involves renal tissue regardless of the aetiology of the leading disease. CKD occurs in one out of every two patients with diabetes mellitus (DM) and appreciably limits the duration and quality of life. CKD can be diagnosed by glomerular filtration rate (GFR), which is recognised as the most representative indicator of the quantity and total workload of nephrons. However, the decrease in GFR occurs at an advanced stage of nephropathy and causes irreversible renal damage, which ultimately requires substitutive renal therapy and, thereby, increases the expense. In this regard, clinical trials have been conducted to identify the biomarkers of CKD reflecting renal damage at earlier stages of the disease. This article presents an overview of modern methods for the diagnosis of CKD and preclinical markers of kidney injury in patients with DM.

KEYWORDS: diabetes mellitus; diabetic nephropathies; biomarkers; glomerular filtration rate

Хроническая болезнь почек (ХБП) - обобщенное понятие, указывающее на поражение почечной ткани вне зависимости от этиологии основного заболевания. Под ХБП понимают наличие любых маркеров повреждения почек, сохраняющихся более 3 мес, и/или стойкое снижение скорости клубочковой фильтрации (СКФ) <60 мл/мин/1,73 м² в течение такого же срока [1]. По статистике, ХБП развивается примерно у 15\% лиц в общей популяции и у каждого второго больного с артериальной гипертензией (АГ) и сахарным диабетом (СД) [2]. Известно, что в России более 7 млн человек имеют повышенный риск развития ХБП, а некоторым из них в будущем может потребоваться лечение экстракорпоральными методами, что превращает медицинскую проблему в социально-экономическую [3]. Согласно исследованию NATION, распространенность сахарного диабета 2 типа (СД2) среди населения России составляет 5,4\% [4], т.е. около 6 млн жителей России имеют СД, а 3 млн - сочетание ХБП и СД.
Ведущую роль в развитии ХБП у больных с СД играет перманентная гипергликемия. Однако несмотря на удовлетворительную компенсацию углеводного обмена, у части пациентов происходит быстрое и прогрессивное снижение функции почек, что указывает на негликемические механизмы [5]. Существенный вклад в прогрессирование ХБП вносят такие факторы, как артериальная гипертензия, дислипидемия, гиперурикемия, инфекционно-воспалительные заболевания почек, поражение сосудов почек, курение, возраст. Также имеются данные о генетической предрасположенности к поражению почек при диабете [6].

В процессе написания статьи использовались следующие базы данных: eLibrary, PubMed, ClinicalTrials.gov, поисковая система Google. Поиск проводился по ключевым словам: хроническая болезнь почек, скорость клубочковой фильтрации, диабетическая нефропатия, ранняя диагностика ХБП. 


\section{СКФ КАК МЕТОД ОЦЕНКИ ПОЧЕЧНОЙ ФУНКЦИИ}

В рутинной практике, руководствуясь Российскими клиническими рекомендациями «Хроническая болезнь почек у больных сахарным диабетом», для диагностики и успешной профилактики развития ХБП используются определение СКФ по креатинину и уровня альбуминурии [7]. К сожалению, эти методы, несмотря на свою информативность, имеют ряд ограничений. Так, преходящее повышение экскреции альбумина возможно при декомпенсации углеводного обмена, высокобелковой диете, после тяжелых физических нагрузок, на фоне лихорадки, при мочевой инфекции и т.д.). По данным H.H. Otu и соавт. (2007), микроальбуминурия не является самым ранним маркером повреждения базальной мембраны клубочка, а снижение СКФ происходит на поздних стадиях нефропатии [8]. Кроме того, у клиницистов часто возникает ситуация, когда выявляется снижение СКФ при нормоальбуминурии. Так, по данным И.И. Трофименко с соавт. (2008), при снижении СКФ<60 мл/мин 8,3\% больных СД 1 типа (СД1) и более 40\% больных СД2 не имеют других проявлений поражений почек (альбуминурии, протеинурии, повышения креатинина в крови). В таком случае врач-эндокринолог не может выставить диагноз диабетической нефропатии (ДН) и назначить лечение. Однако таких пациентов необходимо тщательно наблюдать и контролировать не только показатели гликемии, но и другие факторы риска ХБП: артериальную гипертонию, ожирение, гиперурикемию, дислипидемию, инфекционно-воспалительные процессы в почках и прием нефротоксичных препаратов [9].

В настоящий момент не существует лишенного погрешностей способа расчета СКФ, который мог бы предельно точно оценить фильтрационную способность почек. К наиболее объективным методам оценки СКФ относят расчет клиренса экзогенно вводимых веществ: инулина, этилендиаминтетрауксусной кислоты (51Cr-ЭДТА), диэтилентриаминпентауксусной кислоты (99mTcDTPA), 125I-йоталамата или йодгексола. Эти методы являются «золотым стандартом» диагностики нарушений клубочковой фильтрации, но в связи с высокой стоимостью, трудностью проведения и возможными побочными эффектами использование расчета СКФ экзогенных веществ существенно ограничено. В настоящее время с учетом безопасности и практичности ведущими научными медицинскими сообществами предложено использовать оценку клиренса эндогенных веществ, В частности креатинина, с применением преимущественно расчетных формул. Наиболее точные результаты уровня СКФ, в случае правильного сбора материала для исследования, получают при проведении пробы Реберга-Тареева, которая предполагает оценку 24-часового клиренса креатинина. Однако возможные ошибки при сборе суточной мочи существенно ограничивают использование данного метода. Несмотря на внедрение более простых расчетных способов вычисления СКФ по креатинину, существуют показания для проведения пробы Реберга-Тареева: у лиц с необычным питанием (вегетарианская диета, употребление пищевых добавок с повышенным содержанием креатина, беременность, крайние значения возраста и размеров тела, тяжелая белково-энергетическая недостаточность, заболевания скелетных мышц, параплегия и тетраплегия, быстроменяющаяся функция почек, прием нефротоксичных препаратов) [10].

В течение длительного времени предпринимались попытки создать формулу, учитывающую уровень сывороточного креатинина, а также особенности его метаболизма в организме, гендерные и возрастные различия, не требующую трудоемкого сбора данных. Одной из первых стала формула Кокрофта-Голта (Cockcroft-Gault), для использования которой, кроме креатинина, требуются только возраст, вес и стандартизация на площадь поверхности тела. Однако данная формула была разработана еще до внедрения единых стандартов определения креатинина, а после их введения не была оценена повторно, что делает сомнительной ее валидизацию [11]. Тем не менее, простота использования формулы Кокрофта-Голта, возможность расчета без дополнительных приспособлений в виде нефрологических линеек, калькуляторов и прочего оставляет ее актуальной. Дальнейшие исследования привели к созданию формулы MDRD (Modification of Diet in Renal Disease). Доказано, что данная формула более точная, чем формула Кокрофта-Голта и не требует стандартизации на поверхность тела пациента. Для расчета СКФ с помощью формулы MDRD достаточно показателей уровня креатинина сыворотки крови, пола, возраста и расы пациента, что сделало ее очень практичной для скрининга больных с почечной патологией в амбулаторной практике. Однако проведенная в Англии программа National Kidney Disease Education Program (NKDEP) показала довольно ограниченные возможности в применении данной формулы. Ее использование приемлемо только при СКФ не менее 60 мл/мин/1,73 м² в связи с завышением показателей; а при СКФ более 90 мл/мин/1,73 м² данная формула не может быть использована из-за отсутствия необходимой доказательной базы [12]. В современной практике наиболее валидизированной является формула CKD-EPI, рекомендованная Научным обществом нефрологов России, результаты которой наиболее приближены к реальной СКФ и практически сопоставимы с «золотым стандартом» измерения СКФ [13]. Последний, 8-й выпуск клинических рекомендаций «Алгоритмы специализированной медицинской помощи больным сахарным диабетом» в разделе «Диабетическая нефропатия» предлагает к использованию все перечисленные формулы, однако имеется поправка на лучшее соотношение с референтными методами результатов расчета по формуле CKD-EPI [14]. В рекомендациях KDIGO (Kidney Disease: Improving Global Outcomes, 2012) представлены основные причины ошибок в оценке СКФ (табл. 1), рассчитанной по креатинину [11].

Таким образом, наиболее используемые методы расчета СКФ по креатинину не во всех случаях отражают истинную фильтрационную способность почек и степень их повреждения. В связи с этим в настоящий момент ведутся поиски более ранних и надежных биомаркеров ХБП при СД.

Еще в 2006 г. M.G. Shlipak и соавт. был предложен новый термин - преклиническое заболевание почек. Его стали применять для лиц с сохранной (согласно уровню креатинина) скоростью клубочковой фильтрации, но с повышенным уровнем сывороточного цистати- 
Таблица 1. Причины ошибок при расчете СКФ по уровню креатинина

\begin{tabular}{|c|c|}
\hline Причина ошибки & Пример \\
\hline Неустойчивое состояние & Острое почечное повреждение \\
\hline \multicolumn{2}{|c|}{$\begin{array}{l}\text { Не связанные с СКФ детерминанты СКр, отличающиеся от тех, которые наблюдались в популяциях, в которых разра } \\
\text { батывались формулы }\end{array}$} \\
\hline $\begin{array}{l}\text { Факторы, влияющие на выработку } \\
\text { креатинина }\end{array}$ & $\begin{array}{l}\text { - Иная расовая/этническая принадлежность, чем европеоидная и негроидная } \\
\text { популяции в США и Европе } \\
\text { • Крайние значения мышечной массы } \\
\text { • Крайние значения размера тела } \\
\text { • Диета и нутритивный статус } \\
\text { • Высокобелковая диета } \\
\text { • Дополнительный прием креатина } \\
\text { • Заболевания, приводящие к снижению мышечной массы } \\
\text { •Употребление термически обработанного мяса }\end{array}$ \\
\hline
\end{tabular}

Факторы, влияющие на канальце- Снижение за счет ингибирования, обусловленного лекарственными средствами вую секрецию креатинина (триметоприм, циметидин, фенофибрат)

Факторы, влияющие на внепочеч- • Диализ

- Снижение за счет ингибирования кишечной креатининазы антибиотиками

- Увеличение при большой потере внеклеточной жидкости

Повышение СКФ

- Более высокая биологическая вариабельность не связанных с СКФ детерминант, относящихся к СКФ

- Более высокая погрешность измерения СКр и СКФ

Интерференции при измерении

- Спектральные интерференции (например, билирубин, некоторые лекарствен-

ные препараты)

уровня креатинина

- Химические интерференции (например, глюкоза, кетоны, билирубин, некото-

рые лекарственные препараты)

Примечания: СКр - сывороточный креатинин

на С. Авторами предложено использовать определение цистатина С для выявления пациентов с высоким риском развития ХБП $[15,16]$. Цистатин С - эндогенный белок, обладающий меньшей молекулярной массой, чем креатинин, вырабатывается всеми ядерными клетками организма, беспрепятственно фильтруется клубочками, полностью выводится почками и не секретируется проксимальными канальцами. Все это позволило предположить, что уровень цистатина С может использоваться для определения СКФ. Кроме того, его концентрация практически не зависит от возраста, пола и мышечной массы. Поэтому эксперты KDIGO рекомендуют определение СКФ по цистатину С в случаях, описанных в таблице, а также в случаях ХБП За, но при отсутствии других маркеров почечной патологии и в дополнение к другим методам диагностики ХБП. Существуют формулы, позволяющие более точно оценивать СКФ по уровню цистатина С в крови, чем по уровню креатинина (наибольшее распространение получила формула Хоука (Hoek)) [17]. Наблюдение за $\approx 4500$ пациентов с СД выявило, что цистатин С дает более точное приближение к реальным значениям СКФ, чем креатинин. Авторы полагают, что «цистатин С выявляет важный преклинический период снижения ренальной функции до того момента, когда он сможет быть диагностирован с помощью только креатинина, длительность такого преклинического периода может составлять 10-20 лет» $[15,18]$. Метаанализ исследований, включавших наблюдение более чем за 90 тыс. пациентами, показал, что повышенный уровень цистатина С в моче является маркером нарушения реабсорбции в проксимальных почечных канальцах. Таким образом, измерение цистатина С в моче отражает тубулярную дисфункцию, которая часто предшествует развитию микроальбуминурии $[15,19]$. Однако при исследовании содержания цистатина С в крови и расчете СКФ по его уровню следует принимать во внимание, что на данный показатель оказывают влияние: ожирение (избыточное количество жировой ткани повышает уровень цистатина С в крови), дисфункция щитовидной железы, применение глюкокортикостероидов, наличие антител к цистатину C [20]. Кроме того, в настоящее время доступны биохимические панели для определения цистатина С в крови и моче, но их высокая цена, отсутствие единой методики определения и интерпретации результатов пока ограничивают широкое использование данного метода.

\section{МАРКЕРЫ РАННЕЙ ДИАГНОСТИКИ ХБП}

Для диагностики ХБП используют определение и других маркеров, не требующих расчета СКФ. Одним из таких методов ранней диагностики повреждения почек является определение экскреции коллагена IV типа с мочой. Коллаген IV типа является основной составляющей базальных мембран клубочков и канальцев. Появление этого белка в моче - один из наиболее ранних морфологических признаков Диабетической нефропатии (ДН), возникающий у части пациентов еще до появления альбуминурии; обратно пропорционален уровню СКФ по креатинину [20, 21]. В исследовании И.А. Бондарь и соавт. (2011) выявлено, что мочевая экскреция коллагена IV типа у больных СД1 нарастала по мере увеличения выраженности поражения почек [22]. У пациен- 
тов с нормоальбуминурией зафиксирована тенденция к увеличению почечной экскреции данного маркера по сравнению со здоровыми лицами. Среди больных, которым проведена биопсия почечной ткани, обнаружена избыточная аккумуляция коллагена IV типа в клубочках, которая коррелировала с его высоким содержанием в моче, в том числе и у пациентов с нормоальбуминурией. В данном исследовании повышенная экскреция коллагена была зафиксирована у 39\% больных с нормоальбуминурией. Авторы ссылаются на другие исследования, в которых частота избыточной экскреции коллагена IV типа у больных СД при нормальной экскреции альбумина варьировала от $26 \%$ до $45 \%$. Такая ситуация может встречаться у пациентов, имеющих артериальную гипертензию и некомпенсированное течение СД [23, 24]. Таким образом, повышенное содержание коллагена IV типа в моче может являться доклиническим маркером повреждения почечной ткани, что диктует необходимость проведения дальнейших проспективных исследований.

Широко распространенным фактором риска развития повреждения почек является гиперурикемия (ГУ). Повреждающее воздействие высокого уровня мочевой кислоты (МК) связано с развитием дисфункции эндотелия и постоянного сосудистого воспаления, оксидативным стрессом, адгезией тромбоцитов и нарушением реологических свойств крови [25]. По результатам исследования R.P. Oberbauer и соавт. (2008), была обнаружена корреляция между повышенным риском развития ХБП и увеличением уровня МК в крови на каждый 1 мг/дл [26]. В другом исследовании, изучавшем ГУ как фактор риска развития и прогрессирования ДН у пациентов с СД2, было выявлено, что избыточное содержание МК в крови являлось прогностическим признаком развития персистирующей протеинурии [27]. Уточнение взаимосвязи между развитием и прогрессированием ХБП и гиперурикемией затруднено многочисленными факторами, также оказывающими влияние на темпы снижения почечной функции (гиперлипидемия, артериальная гипертензия, ожирение и пр.). В настоящий момент возможно применение специальных формул для расчета клиренса МК или ее экскретируемой фракции, однако в практической медицине это используется для выявления уратного повреждения почек и не получило широкого распространения для диагностики ХБП у больных СД [28]. Использование наиболее достоверного метода оценки вклада ГУ в ХБП - прижизненной биопсии почек с морфологическим исследованием биоптата, существенно ограничено в рутинной практике.

На сегодня продолжается поиск новых ранних биомаркеров диагностики ХБП. Одним из таких маркеров является N-ацетил- $\beta$-D-глюкозаминидаза (NAG). NAG крупномолекулярный белок, который у здоровых лиц не проходит через гломерулярный барьер, поэтому этот фермент начинает определяться в моче при повреждении почечного эпителия, патогномоничного для СД. В ряде работ показано, что увеличение мочевой экскреции NAG выявляется еще до появления микроальбуминурии [29]. В других исследованиях выявлено, что повышенная экскреция NAG - независимый фактор развития МАУ и макроальбуминурии. На основании этих данных был сделан вывод, что у пациентов с СД1 измерение NAG в моче может служить не менее информативным маркером ДН, чем исследование уровня альбуминурии. A. Mohammadi-Karakani и соавт. (2007) показали, что тест на содержание NAG обладает высокой чувствительностью и специфичностью - 100\% и 87,5\% соответственно, и предложили использовать его в клинической практике [30].

Ряд авторов для ранней диагностики ХБП у больных с СД предлагают использовать уровень липокалина, ассоциированного с желатиназой нейтрофилов (neutrophil gelatinase-associated lipocalin, NGAL), - специфического белка, уровень которого в плазме крови при развитии ренальных дисфункций постепенно возрастает и коррелирует с тяжестью патологии [31]. В настоящий момент NGAL мочи также рассматривается в качестве маркера ХБП и ее тяжести. При ХБП повышение уровня NGAL в моче достоверно коррелирует с ростом концентрации сывороточного креатинина, степенью снижения СКФ и выраженностью протеинурии. D. Bolignano и соавт. (2009) сообщают, что повышенное содержание NGAL в моче ассоциировано с протеинурией и прогрессированием ХБП [32].

В качестве доклинической диагностики ХБП у пациентов с СД может быть использовано определение количества подоцитов в моче. Исследования показали, что после повреждения подоцитов снижается их адгезия к базальной мембране клубочков и возрастает экскреция подоцитов с мочой. Следовательно, подоцитурия также может быть ранним маркером повреждения почек у пациентов с СД [33]. С. Granier и соавт. (2008) выявили, что подоцитурия увеличивалась по мере прогрессирования диабетической нефропатии: так, на стадии микроальбуминурии она определялась у половины пациентов, а на стадии протеинурии - у 80\% обследованных. Лечение препаратами, блокирующими ренин-ангиотензин-альдостероновую систему, приводило к значимому снижению не только уровня альбуминурии, но и подоцитурии [34]. Согласно последним данным, при СД наблюдается положительная корреляция между концентрацией мочевого подокаликсина (белка на поверхности подоцитов) и уровнем гликированного гемоглобина [35].

При изучении мочевого осадка у пациентов с СД на различных стадиях ХБП было обнаружено большое количество специфических белков, которым отводят роль маркеров раннего повреждения почек. К ним относят такие белки, как Е-кадгерин и орозомукоид (UOER). Е-кадгерин - одна из наиболее значимых молекул клеточной адгезии в эпителиальных тканях. Роль Е-кадгерина состоит в формировании эпителиального пласта, а также в обеспечении межклеточной адгезии, клеточной пролиферации и дифференцировки. При исследовании больных СД было выявлено, что содержание Е-кадгерина в моче было повышено по сравнению с контрольной группой, в 1,3 раза при нормальном содержании альбумина в моче и в 5,2 раза при микроальбуминурии. Кроме того, было выявлено значительное снижение Е-кадгерина в клетках почечных канальцев при диабетической нефропатии [36, 37]. У пациентов с диабетической нефропатией выявлено повышение в моче концентрации белка UOER более чем в восемь раз, а также обнаружена положительная корреляция UOER с экскрецией альбумина с мочой, уровнем креатинина и С-реактивного белка 
сыворотки крови. Согласно исследованиям, увеличение концентрации UOER в моче является независимым фактором риска развития ДН [37].

Помимо вышеперечисленных белков, которые доказали свою роль в формировании ХБП у больных с СД, продолжается изучение и других маркеров - например, KIM-1 (Kidney Injury Molecule-1, молекула повреждения почек), некоторых интерлейкинов (ИЛ-1 $\beta$ и ИЛ-8), асимметричного диметиларгинина (ADMA), печеночного (L) типа СЖК-связывающего протеина, моноцитарного хемоаттрактантного протеина (МСР-1), ретинолсвязывающе-

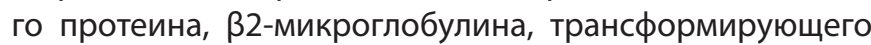
фактора роста- $\beta$ (TGF- $\beta$ ), уромодулина, ретинолсвязывающего белка (RBP) и многих других [38]. В настоящий момент доказано, что данные маркеры появляются при различных повреждениях почек, обсуждаются сроки реализации и прогностическая ценность, но установление информативности данных показателей и их вклада в патогенез нефропатии при СД требует дальнейшего изучения [39].

\section{ГЕНЕТИЧЕСКИЕ АСПЕКТЫ ФОРМИРОВАНИЯ ХБП}

В настоящее время, кроме поиска новых способов диагностики ХБП и ранних биохимических маркеров ренального поражения, проводится изучение генетической детерминированности развития ХБП при СД. В книге «Сахарный диабет и хроническая болезнь почек» [40] целая глава посвящена генетике ДН и отмечено, что подавляющее большинство исследований, посвященных генетической детерминированности ДН, проведено на пациентах с СД1. Представлены гены, кодирующие продукцию вазоактивных веществ, факторы липидного обмена, интегральных белков мембран и внеклеточного матрикса, альдозоредуктазы (ALR2), метилентетрагидрофолатредуктазы, интерлейкина-1, и другие гены-кандидаты. Несомненно, значительно меньшее количество исследований по генетической детерминированности ХБП при СД2 связано с мультифакториальным патогенезом СД2 и его гетерогенностью.

Однако появляются исследования генетического фактора и при СД2. Так, А.В. Железнякова и соавт. (2014) в своей работе выявили достоверную взаимос- вязь между риском развития ХБП и генами, кодирующими факторы эндотелия (NOS3), факторы липидного обмена (APOB) и факторы секреции инсулина (KCNJ11, TCF7L2). Носительство одних аллелей и генотипов этих генов имеет нефропротекторный механизм, а других наоборот, повышает риск развития ХБП. Авторами выявлено, что развитие альбуминурии ассоциировано с полиморфным маркером есNOS4a/4b гена NOS3, а снижение СКФ - с комплексом полиморфных маркеров ecNOS4a/4b гена NOS3, I/D гена $A P O B, r s 5219$ гена KCNJ11, rs7903146 гена TCF7L2. Сделано заключение, что основные клинические маркеры поражения почек (СКФ и уровень альбуминурии) и их патогенетические механизмы принципиально отличаются даже на генетическом уровне [41]. Из этого следует, что превентивное проведение генетического исследования может внести вклад в определение групп риска больных СД по развитию ХБП и вовремя начать профилактические мероприятия.

\section{ЗАКЛЮЧЕНИЕ}

Таким образом, используемые в современной медицине методы оценки функции почек (уровень креатинина, СКФ по креатинину, альбуминурия) выявляют нарушения уже на этапе повреждения клубочка и не могут во всех случаях служить предикторами развития ХБП. Это обуславливает поиск новых биохимических и генетических маркеров на доклиническом этапе, что позволит предупредить или отсрочить развитие почечной патологии у больных с СД, инициировать своевременную нефропротективную терапию и снизить экономические затраты на заместительную почечную терапию [42].

\section{ДОПОЛНИТЕЛЬНАЯ ИНФОРМАЦИЯ}

Конфликт интересов. Авторы декларируют отсутствие явных и потенциальных конфликтов интересов, связанных с публикацией настоящей статьи.

Участие авторов. Маркова Т.Н. - концепция, дизайн и редактирование статьи; Садовская В.В. - анализ литературных данных, обработка исходного материала, написание текста; Беспятова М.Ю. - поиск актуальной литературы.

\section{СПИСОК ЛИТЕРАТУРЫ | REFERENCES}

1. Швецов М.Ю., Бобкова И.Н., Колина И.Б., Камышова Е.В. Хроническая болезнь почек и нефропротективная терапия. Методическое руководство для врачей. / Под ред. Шилова Е.М. - М., 2012. [Shvetsov MY, Bobkova IN, Kolina IB, Kamishova EV. Khronicheskaya bolezn' pochek i nefroprotektivnaya terapiya. Metodicheskoe rukovodstvo dlya vrachey. Shilov EM, editor. Moscow; 2012. (In Russ.)]

2. Маслова О.В., Сунцов Ю.И., Шестакова М.В., и др. Распространенность поражения почек при сахарном диабете 1 и 2 типов в Российской Федерации // Сахарный диабет. - 2009. - Т. 12. - №4. C. 47-51. [Maslova OV, Suntsov YI, Shestakova MV, et al. Prevalence of renal lesions in patients with type 1 and 2 diabetes mellitus in the Russian Federation. Diabetes mellitus. 2009;12(4):47-51. (In Russ.)] doi: 10.14341/2072-0351-5704

3. Шестакова М.В., Лепетухин А.Е., Кварацхелия М.В., Дедов И.И. Особенности ведения больных сахарным диабетом с терминальной почечной недостаточностью на программном гемодиализе // Терапевтический архив. - 2004. - Т. 76. - №9. - С. 70-74. [Shestakova MV, Lepetukhin AE, Kvaratskheliya MV, Dedov II. Management of patients with diabetes mellitus with terminal renal failure on programmed hemodialysis. Terapevticheskij arkhiv. 2004;76(9):70-74. (In Russ.)]

4. Дедов И.И., Шестакова М.В., Галстян Г.Р. Распространенность сахарного диабета 2 типа у взрослого населения России (исследование NATION) // Сахарный диабет. - 2016. - T. 19. - №2. C. 104-112. [Dedov II, Shestakova MV, Galstyan GR. The prevalence of type 2 diabetes mellitus in the adult population of Russia (NATION study). Diabetes mellitus. 2016;19(2):104-112. (In Russ)] doi: 10.14341/DM2004116-17

5. Fogarty DG, Rich SS, Hanna L, et al. Urinary albumin excretion in families with type 2 diabetes is heritable and genetically correlated to blood pressure. Kidney Int. 2000;57(1):250-257. doi: 10.1046/j.1523-1755.2000.00833.x

6. Seaquist ER, Goetz FC, Rich S, Barbosa J. Familial clustering of diabetic kidney disease. Evidence for genetic susceptibility to diabetic nephropathy. N Engl J Med. 1989;320(18):1161-1165. doi: 10.1056/NEJM198905043201801 
7. Российсие клинические рекомендации. Хроническая болезнь почек у больных сахарным диабетом / Под ред. Дедова И.И., Мельниченко Г.А. - М.: ГЭОТАР-Медиа, 2016. [Dedov II, Mel'nichenko GA, editors. Rossiysie klinicheskie rekomendatsii. Khronicheskaya bolezn' pochek u bol'nykh sakharnym diabetom. Moscow: GEOTAR-Media; 2016. (In Russ.)]

8. Otu HH, Can H, Spentzos D, et al. Prediction of diabetic nephropathy using urine proteomic profiling 10 years prior to development of nephropathy. Diabetes Care. 2007;30(3):638-643. doi: $10.2337 /$ dc06-1656

9. Трофименко И.И., Добронравов В.А., Быстрова Н.Н., и др. Распространенность снижения скорости клубочковой фильрации у больных сахарным диабетом // Терапевтический архив. - 2008. T. 80. - №6. - C. 48-52. [Trofimenko II, Dobronravov VA, Bystrova NN, et al. Rasprostranennost' snizheniya skorosti klubochkovoy fil'ratsii u bol'nykh sakharnym diabetom. Terapevticheskij arkhiv. 2008;80(6):48-52. (In Russ.)]

10. Моисеев В.С., Мухин Н.А., Смирнов А.В. Сердечно-сосудистый риск и хроническая болезнь почек: стратегии кардио-нефропротекции // Российский кардиологический журнал. - 2014. №8. - C. 7-37. [Moiseev VC, Mukhin NA, Smirnov AV. Cardiovascular risk and chronic kidney disease: cardio-nephroprotection strategies. Russian Journal of Cardiology. 2014;(8):7-37. (In Russ.)] doi: 10.15829/1560-4071-2014-8-7-37

11. KDIGO 2012 clinical practice guideline for the evaluation and management of chronic kidney disease. Kidney Int Suppl. 2013;3(1):1-150.

12. Батюшин М.М. Методические основы оценки скорости клубочковой фильтрации в урологической практике // Becmникурологии. - 2017. - Т. 5. - №1. - C. 42-51. [Batiushin MM. Methodical bases of estimation glomerular filtration rate in urological practice. Vestnik urologii. 2017;5(1):42-51. (In Russ.)] doi: 10.21886/2306-6424-2017-5-1-42-51

13. Шилов Е.М., Добронравов В.А., Каюков И.Г. и др. Начиональные рекомендачии. Хроническая болезнь почек: основные принципы скрининга, диагностики, профилактики и подходы к лечению. Спб:: Издательство Левша, 2012. [Shilov EM, Dobronravov VA, Kayukov IG, et al. Natsional'nye rekomendatsii. Khronicheskaya bolezn' pochek: osnovnye printsipy skrininga, diagnostiki, profilaktiki i podkhody klecheniyu. Saint Petersburg: Izdatel'stvo «Levsha»; 2012. (In Russ.)]

14. Дедов И.И., Шестакова М.В., Майоров А.Ю., и др. Алгоритмы специализированной медицинской помощи больным сахарным диабетом / Под редакцией И.И. Дедова, М.В. Шестаковой, А.Ю. Майорова. - 8-й выпуск // Сахарный диабет. - 2017. T. 20. - №1S. - C. 1-121. [Dedov II, Shestakova MV, Mayorov AY, et al. Standards of specialized diabetes care. Edited by Dedov II, Shestakova MV, Mayorov AY. 8th edition. Diabetes mellitus. 2017;20(1S):1-121. (In Russ.)] doi: 10.14341/DM8146

15. Вельков В.В. Цистатин с и NGAL - маркеры преклинической ренальной дисфункции и субклинического острого повреждения почек // Лабораторная служба. - 2015. - Т. 4. - №2. - С. 38-43. [Vel'kov V.V. Cystatin C and NGAL - the markers of preclinical renal dysfuction and subclinical acute kidney injury. Laboratornaya sluzhba. 2015;4(2):38-43. (In Russ.)] doi: 10.17116/labs20154238-43

16. Shlipak MG, Katz R, Sarnak MJ, et al. Cystatin C and prognosis for cardiovascular and kidney outcomes in elderly persons without chronic kidney disease. Ann Intern Med. 2006;145(4):237-246. doi: 10.7326/0003-4819-145-4-200608150-00003

17. Байрашева В.К., Бабенко А.Ю., Байрамов А.А., и др. Перспективы нефропротекции при сахарном диабете 2-го типа с использованием ингибитора ДПП-4 вилдаглиптина // Медицинский совет. 2017. - №3. - C. 8-16. [Bayrasheva VK, Babenko AY, Bayramov AA et al. Prospects of nephroprotection against type 2 diabetes using the dpp-4 inhibitor vildagliptin. Medical Council. 2017;(3):8-16. (In Russ.)] doi: 10.21518/2079-701X-2017-3-8-16

18. Shlipak MG, Matsushita K, Ärnlöv J. Cystatin C versus creatinine in determining risk based on kidney function. N Engl J Med. 2013:369(10):932-943. doi: 10.1056/NEJMoa1214234

19. Zhang Z, Lu B, Sheng X, Jin N. Cystatin C in prediction of acute kidney injury: a systemic review and meta-analysis. Am J Kidney Dis. 2011;58(3):356-65. doi: 10.1053/j.ajkd.2011.02.389

20. Климонтов В.В., Еременко Н.В., Мякина Н.Е., Фазуллина О.Н. Цистатин C и коллаген IV типа в диагностике хронической болезни почек у больных сахарным диабетом 2 типа // Сахарный диа6em. - 2015. - T. 18. - №1. - C. 87-93. [Klimontov VV, Eremenko NV, Myakina NE, Fazullina ON. Cystatin C and collagen type IV in diag- nostics of chronic kidney disease in type 2 diabetic patients. Diabetes mellitus. 2015:18(1):87-93. (In Russ.)] doi: 10.14341/DM2015187-93

21. Okonogi $\mathrm{H}$, Nishimura M, Utsunomiya Y, et al. Urinary type IV collagen excretion reflects renal morphological alterations and type IV collagen expression in patients with type 2 diabetes mellitus. Clin Nephrol. 2001;55(5):357-364

22. Бондарь И.А., Климонтов В.В., Парфентьева Е.М., и др. Мочевая экскреция коллагена IV типа - ранний маркер фиброзирования почек при сахарном диабете // Сахарный диабет. - 2011. - Т. 14. №4. - C. 29-31. [Bondar' IA, Klimontov W, Parfent'eva EM, et al Urinary excretion of type IV collagen as an early marker of renal fibrosis in patients with diabetes mellitus. Diabetes mellitus. 2011;14(4):29-31. (In Russ.)] doi: 10.14341/2072-0351-5813

23. Cawood TJ, Bashir M, Brady J, et al. Urinary collagen IV and TGST: potential biomarkers for detecting localized kidney injury in diabetes-a pilot study. Am J Nephrol. 2010;32(3):219-225. doi: 10.1159/000317531

24. lijima T, Suzuki S, Sekizuka K, et al. Follow-up study on urinary type IV collagen in patients with early stage diabetic nephropathy. J Clin Lab Anal. 1998;12(6):378-382. doi: 10.1002/(SICI)1098-2825(1998)12:6<378::AID-JCLA8>3.0.CO;2-J

25. К Кобалава Ж.Д., Котовская Ю.В., Толкачева В.В., Мильто А.С. Мочевая кислота - ключевой компонент кардиренометаболического континуума // Кардиоваскулярная терапия и профилактика. 2008. - T. 7. - №4. - C. 95-100. [Kobalava ZhD., Kotovskaya YuV, Tolkacheva WV, Milto AS. Uric acid - the key component of "cardio-reno-metabolic continuum". Cardiovascular Therapy and Prevention. 2008;7(4):95-100. (In Russ.)]

26. Oberbauer RP, Temml C, Gutjahr G, et al. Elevated uric acid increases the risk for kidney disease. J Am Soc Nephrol. 2008;19(12):2407-2413. doi: 10.1681/ASN.2008010080

27. Jalal DJ, Maahs DM, Hovind P, Nakagawa T. Uric acid as a mediator of diabetic nephropathy. Semin Nephrol. 2011;31(5):459-465 doi: 10.1016/j.semnephrol.2011.08.011

28. Максудова А.Н., Халфина Т.Н. Функции почек у больных подагрой без признаков хронической болезни почек. // Нефрология и диализ. - 2012. - T. 14. - №1. - С. 62-67. [Maksudova AN., Khalfina TN. Funktsii pochek u bol'nykh podagroy bez priznakov khronicheskoy bolezni pochek. Nefrologiva i dializ. 2012;14(1):62-67. (In Russ.)]

29. Nauta FL, Boertien WE, Bakker SJ, et al. Glomerular and tubular damage markers are elevated in patients with diabetes. Diabetes Care. 2011;34(4):975-981. doi: 10.2337/dc10-1545

30. Mohammadi-Karakani A, Asgharzadeh-Haghighi S, Ghazi-Khansari M, Hosseini R. Determination of urinary enzymes as a marker of early renal damage in diabetic patients. J Clin Lab Anal. 2007;21 (6):413-417. doi: 10.1002/jcla.20212

31. Woo KS, Choi JL, Kim BR, et al. Urinary neutrophil gelatinase-associated lipocalin levels in comparison with glomerular filtration rate for evaluation of renal function in patients with diabetic chronic kidney disease. Diabetes Metab J. 2012;36(4):307-313. doi: 10.4093/dmj.2012.36.4.307

32. Bolignano D, Lacquaniti A, Coppolino G, et al. Neutrophil gelatinase-associated lipocalin (NGAL) and progression of chronic kidney disease. Clin J Am Soc Nephrol. 2009;(4):337-344. doi: 10.2215/CJN.03530708

33. Бобкова И.Н., Шестакова М.В., Щукина А.А. Повреждение подоцитов при сахарном диабете // Сахарный диабет. - 2014. - Т. 17. №3. - C. 39-50. [Bobkova IN, Shestakova MV, Shchukina AA. Podocyte injury in diabetes mellitus. Diabetes mellitus. 2014;17(3):39-50. (In Russ.)] doi: 10.14341/DM2014339-50

34. Granier C, Makni K, Molina L, et al. Gene and protein markers of diabetic nephropathy. Nephrol Dial Transplant. 2008;23(3):792-799. doi: 10.1093/ndt/gfm834

35. Hara M, Yamagata K, Tomino Y, et al. Urinary podocalyxin is an early marker for podocyte injury in patients with diabetes: establishment of a highly sensitive ELISA to detect urinary podocalyxin. Diabetologia, 2012;55(11):2913-2919. doi: 10.1007/s00125-012-2661-7

36. Jiang H, Guan G, Zhang R, et al. Identification of urinary soluble E-cadherin as a novel biomarker for diabetic nephropathy. Diabetes Metab Res Rev. 2009:25(3):232-241. doi: 10.1002/dmrr.940

37. Алексеев А.В., Гильманов А.Ж., Гатиятуллина Р.С., Ракипов И.Г. Современные биомаркеры острого повреждения почек // Практическая медицина. - 2014. - №3. - C. 22-27. [Alekseev AV, Gil'manov AZh, Gatiyatullina RS, Rakipov IG. Recent biomarkers of acute renal injury. Practical medicine. 2014;(3):22-27. (In Russ.)] 
38. Шамхалова М.Ш., Курумова К.О., Клефортова И.И., и др. Факторы развития туболоинтерстициального повреждения почек у больных сахарным диабетом // Сахарный диабет. - 2010. - Т. 13. №3. - C. 134-141. [Shamkhalova MSh, Kurumova KO, Klefortova II, et al. Factors promoting development of renal tubulointerstitial lesions in patients with diabetes mellitus. Diabetes mellitus. 2010;13(3):134-141. (In Russ.)] doi: 10.14341/2072-0351-5502

39. Бондарь И.А., Климонтов В.В. Ранние маркеры диабетической нефропатии // Клиническая несрология. - 2010. - №2. - С. 60-65. [Bondar IA, Klimontov W. Early markers of diabetic nephropathy. Clinical Nephrology. 2010;(2):60-65. (In Russ.)]

40. Шестакова М.В., Дедов И.И. Сахарный диабет и хроническая болезнь почек. - М.: ООО «Медицинское информационное агентСтво», 2009. [Shestakova MV, Dedov II. Sakharnyy diabet i khronicheskaya bolezn' pochek. Moscow: 000 «Meditsinskoe informatsionnoe agentstvo»; 2009. (In Russ.)]
41. Железнякова А.В., Лебедева Н.О., Викулова О.К., и др. Риск развития хронической болезни почек у больных сахарным диабетом 2 типа детерминирован полиморфизмом генов NOS3, APOB, KCNJ11, TCF7L2 // Сахарный duaбem. - 2014. - T. 17. - №3. - C. 23-30. [Zheleznyakova AV, Lebedeva NO, Vikulova OK, et al. Risk of chronic kidney disease in type 2 diabetes determined by polymorphisms in NOS3, APOB, KCNJ11, TCF7L2 genes as compound effect of risk genotypes combination. Diabetes mellitus. 2014;17(3):23-30. (In Russ.)] doi: 10.14341/DM2014323-30

42. Шестакова М.В., Шамхалова М.Ш., Ярек-Мартынова И.Я., и др. Сахарный диабет и хроническая болезнь почек: достижения, нерешенные проблемы и перспективы лечения // Сахарный duaбem. - 2011. - T. 14. - №1. - C. 81-88. [Shestakova MV, Shamkhalova MSh, Yarek-Martynova IY, et al. Diabetes mellitus and chronic kidney disease: achievements, unresolved problems, and prospects for therapy. Diabetes mellitus. 2011;14(1):81-88. (In Russ.)] doi: 10.14341/2072-0351-6254

\section{ИНФОРМАЦИЯ ОБ АВТОРАХ [AUTHORS INFO]}

Садовская Виктория Викторовна, клинический ординатор [Viktoriia V. Sadovskaya, clinical resident]; адрес: Россия, 127473, Москва, ул. Делегатская, д. 20, стр. 1 [address: 20/1 Delegatskaja street, Moscow, 127473 Russian Federation]; ORCID: http://orcid.org/0000-0002-4602-1443; eLibrary SPIN: 1663-3693; e-mail: sviridvika@yandex.ru

Маркова Татьяна Николаевна, А.М.н., профессор [Tatiana N. Markova, MD, PhD]; ORCID: http://orcid.org/0000-0002-8798-887X; eLibrary SPIN: 5914-2890; e-mail: markovatn18@yandex.ru. Беспятова Марина Юрьевна, врач-эндокринолог [Marina Y. Bespyatova, MD]; ORCID: http://orcid.org/0000-0002-8557-944X; e-mail: bespyatovam@mail.ru

\section{ЦИТИРОВАТЬ:}

Маркова Т.Н., Садовская В.В., Беспятова М.Ю. Современные возможности диагностики хронической болезни почек при сахарном диабете // Сахарный диабет. — 2017. — T. 20. — №6. — C. 454-460. doi: 10.14341/DM9268

\section{TO CITE THIS ARTICLE:}

Markova TN, Sadovskaya VV, Bespyatova MY. Modern methods of diagnosing chronic kidney disease in patients with diabetes mellitus . Diabetes mellitus. 2017;20(6):454-460. doi: 10.14341/DM9268 